\title{
LAS DESTREZAS LEGALES EN LA ENSEÑANZA DEL DERECHO: EL CASO DE LAS COMPETENCIAS DE ESTUDIANTES
}

Victor Madrid Horna*

\section{RESUMEN}

El estudio del derecho no se agota en el estudio de las categorías jurídicas y las instituciones, sino que refiere del aprendizaje de ciertas destrezas legales. En este artículo se repasa la importancia de estas destrezas como parte del estudio del Derecho en pre-grado.

\section{ABSTRACT}

The study of law is not exhausted by the study of legal categories ans institutions, but refers to the learning of vertain legal skills. This article reviews the importance of these skills as part of the study of pre-degree law.

\section{PALABRAS CLAVE}

Enseñanza del Derecho. Destrezas legales. Competencia

\section{KEYWORDS}

Teaching of the law. Legal skills. Competition.

Desde que empecé a estudiar la carrera de derecho fui testigo de las numerosas discusiones generadas en torno a cómo debería estructurarse el plan de estudios y cuáles deberían ser los criterios para organizar la malla curricular de manera que se cumplan las exigencias académicas que logren de modo más eficiente los fines pretendidos por nuestra facultad para formar abogados. Es decir, la visión de cómo enseñar el derecho ha sido una permanente preocupación en- tre los docentes y autoridades universitarias que terminaba en algunas reformas o proyectos curriculares, no siempre bien recibidos ${ }^{1}$.

No cabe duda que en los últimos años el contenido y la estructu-

* Abogado por la Pontificia Universidad Católica del Perú. Profesor de derecho civil patrimonial en las facultades de derecho de la Universidad Femenina del Sagrado Corazón, Pontificia Universidad Católica del Perú y Universidad del Pacifico. Árbitro. Jurado de las VII (Lima) VIII (Santiago de Chile) y IX (Montevideo) Edición de la Competencia Internacional de Arbitraje organizada por la Universidad de Buenos Aires -UBA (Argentina) y la Universidad de Rosario de Bogotá (Colombia).

1 Para una referencia general sobre la evolución de esta reflexión y discusión a través de los años en la facultad de derecho de la PUCP puede consultarse: DE TRAZEGNIES, Fernando, AVENDAÑO Jorge y ZOLEZZI, Lorenzo: "Nuestra reforma de la enseñanza del Derecho", en DERECHO PUCP, revista de la Facultad de Derecho de la PUCP, N²9, Lima 1971; ZOLEZZI IBARCENA, Lorenzo: “Formación del abogado y sociedad: balance y perspectivas", en DERECHO PUCP, revista de la Facultad de Derecho de la PUCP, Lima N 45; RUBIO CORREA, Marcial, "Proyecto de nuevo Sistema de Enseñanza del derecho en la facultad de Derecho de la Pontificia Universidad Católica del Perú", en DERECHO PUCP, Revista de la Facultad de Derecho de la PUCP, Lima N 52, Lima 1999; GONZÁLES MANTILLA, Gorki: “La enseñanza del derecho en el Perú: cambios, resistencias y continuidades”, en Clínicas de interés público y enseñanzas del derecho. Cuadernos de Análisis Jurídico $N^{\circ} 15$, Santiago de Chile, Facultad de Derecho. Universidad Diego Portales, 2003; BOZA DIBÓS. Beatriz: “La abogacía: ¿profesión o empresa?" Nuevos desafíos para el ejercicio profesional del abogado" en Libro Homenaje a Jorge Avendaño, Fondo Editorial de la Pontificia Universidad Católica del Perú, Tomo I, Lima, 2004. 
ra de las mallas curriculares de la carrera de derecho en las distintas facultades de derecho de nuestro país han venido experimentando numerosos cambios y replanteos. $Y$ es que si bien existen áreas o especialidades más o menos definidas en todas las facultades de derecho, la idea de un orden, o de un énfasis, o de un método específico para enseñar ha guiado distintas maneras de concebir la enseñanza del derecho, que por cierto tiene como telón de fondo la visión misma del derecho y del abogado que se pretende forjar.

Una primera razón que explica esta razonable preocupación es la constante dinámica del derecho que se renueva y plantea nuevos retos que van de la mano con las necesidades de nuevos desafíos legales que afronta la sociedad y el mercado.

De este modo, una breve revisión de las mallas curriculares de las distintas facultades de derecho de nuestro país en los últimos 10 años por ejemplo, permite observar un permanente cambio en algunos casos y el seguimiento de ciertas tendencias en otros, producidos de seguro por una particular visión del derecho a veces ligado a determinados principios o visiones del derecho y por la idea que cada casa de estudios tiene sobre los propósitos que la enseñanza debe imprimir en sus alumnos.

Querámoslo o no, el mercado laboral de los futuros abogados también tiene un impacto en la forma como las escuelas de derecho alistan sus ofertas académicas. $Y$ es que no cabe duda que las demandas del mercado y su proyección en las encuestas o percepciones sobre la colocación de abogados en el mercado muchas veces inspiran cambios en las estructuras curriculares, ya sea planteando abreviar la carrera u ofreciendo cursos presuntamente requeridos por el mercado hasta llegar a las ofertas de carreras on line, promocionadas a través de ofertas educativas dirigidas a un público con cada vez más opciones.

Ya para el año 2011, como lo señala MAC LEAN², se advertía un crecimiento exponencial de las facultades de derecho generando una "competencia" de ofertas. Si en el año 1997 existían 33 facultades de derecho inscritas en la Asamblea Nacional de Rectores ya para el año 2011 había 66 facultades de derecho inscritas, número que aún se ha incrementado a la fecha. Este crecimiento sin embargo, no fue de la mano con el crecimiento en calidad de la enseñanza sino y por el contrario generó el debate sobre si era necesario regular desde el Estado el número de facultades o escuelas de leyes, habida cuenta de la sobre oferta de abogados y la masificación de una enseñanza muchas veces dudosa

\section{Estudiar derecho}

Debo decir que me gusta el derecho y desde que salí del colegio quise convertirme en abogado, aunque años después confirmé la gran diferencia que existe entre el derecho y la abogacía. Y es que muchas veces el ejercicio profesional implica un desempeño que se aleja del derecho y sobre todo de ese derecho expresado en los puros contenidos teóricos y de laboratorio que aprendimos en las aulas.

Cuando egresé de la facultad de derecho de seguro experimenté una sensación que a acompañado a cientos de abogados.

Tuve la oportunidad de aprender la carrera de derecho en una facultad dotaba de muchos buenos y destacados profesores a quienes debo agradecer mucho de lo que aprendí. Como muchos, asistía a mis clases a cargo de los docentes de cátedra y a las clases prácticas de algunos cursos donde se desarrollaban casos y se complementaban temas de clase a cargo de jefes de práctica, sin perjuicio de asistir a cuanto evento académico de mi interés se organizaba.

De esta forma, al finalizar la carrera, estuve seguro de contar con los conocimientos necesarios para el ejercicio de la profesión y que las prácticas pre profesionales -como una necesaria etapa previa al ejercicio profesional-, me acercaría más al terreno práctico a fin de poner en ejecución lo aprendido y ver y conocer el mundo real donde el derecho se desarrolla.

Sin embargo, la experiencia pre profesional y luego la

2 MAC LEAN MARTINS, Ana Cecilia, en "Escuela de Postgrado de la UPC CUADERNOS DE INVESTIGACIÓN EPG Edición Nº 14 - Abril 2011. Lima, Perú. Pág. 6. 
profesional me hicieron una y otra vez pensar si mi aprendizaje había sido del todo completo o si era yo el que carecía del talento suficiente para adaptarme al ejercicio de la profesión.

Y es que mi primera sensación fue que los conocimientos adquiridos durante los años de la carrera lucían ajenos, desconectados y a veces hasta insuficientes para poder llevar a cabo las labores más elementales que mis primeras prácticas me exigían. Comprendí que redactar una carta, o entender el alcance de una norma, o elaborar un informe, o preparar un escrito de alegatos, o asistir a una reunión con algún cliente para tomar nota, requería de una serie de destrezas o competencias que sólo la experiencia me daría, porque de hecho no me sentía preparado para ello, pese a mis seguros conocimientos legales.

Ello explica porque no resulta extraño que las primeras tareas de un practicante ya sea en un estudio de abogados, en una empresa o en una entidad del Estado, por ejemplo, empiecen con sencillas labores administrativas, como la lectura o revisión de expedientes, revisión de información legal, entre otras y sobre todo con un rol de permanente apoyo a otras personas que permita ver y aprender el oficio de abogado desde dentro.

Conforme avanzaba en las responsabilidades que se me asignaban, sentía que más co- sas me faltaban por aprender. Nunca había estado frente a un Juez y tener que explicar un caso en pocos minutos, o sustentar un recurso me parecía una labor que poco tenía que ver con mis conocimientos de derecho. Alcanzar la redacción precisa no me resultaba una tarea sencilla, y explicar en forma directa los hechos de un caso se me hacía siempre complicado. Cuando se nos encargaba una labor de investigación tomaba más tiempo en saber por dónde empezar y ello me convencía que estaba en medio de un constante aprendizaje empírico y que mis conocimientos jurídicos tenían que conectarse en algún momento con todo esto.

Siempre tuve la idea que de un modo u otro, este era el inevitable peregrinaje que todo abogado debía seguir. Con el tiempo, aprendí que el ejercicio profesional es posible solo gracias a este proceso de aprendizaje donde se fusionan el saber jurídico y ciertas competencias que sólo la experiencia y el esfuerzo pueden conseguir.

Tal y como lo señala MORALES LUNA, Félix: "El objetivo de un proceso de enseñanza del derecho consiste, a nuestro entender, de una parte, en mostrar al alumno qué es el derecho y cómo funciona en la realidad y, de otra, dotarle de herramientas teóricas, prácticas y éticas para que, siendo profesional del derecho, pueda ser abogado, juez, funcionario o cualquier otro rol que tuviera que asumir. En tal sentido, es tanta la responsabilidad que importa esta etapa como también los riesgos que suponen eventuales deficiencias. En efecto, si al alumno se le presenta y se le forma en una idea del derecho que no refleja ni reconstruye adecuadamente las prácticas jurídicas reales, durante su ejercicio profesional advertirá el desfase entre, por así decirlo, el derecho en el aula y el derecho en la realidad. De esta forma, para desenvolverse en este último, tendría que adoptar las prácticas usuales entre los profesionales del derecho y aprendería su profesión mientras lo ejerce y ya siendo profesional. Más aún, no siendo infrecuente que este profesional tuviera ocasión de llegar a la docencia, con su enseñanza contribuiría a perpetuar esa idea del derecho que aprendió, y creemos transmitiría una idea artificial, parcial o errada de este, junto con ciertos consejos que permitan a sus alumnos suplir las deficiencias conceptuales de aquella y que les permita desempeñarse con suficiencia en el ejercicio de la profesión."

El aprendizaje del derecho tiene por objeto dotar a los alumnos de conocimiento legal en su más amplio sentido, pero no solo de conocimiento.

Este conocimiento de las materias legales se van impartiendo desde los primeros ciclos en el orden más lógico y progresivo posible a fin de que el alumno vaya familiarizándose y conociendo las materias básicas hasta los cursos que requieren de varios cursos pre requisito

3 MORALES LUNA, Félix F. “Cambios en el Derecho, cambios en su enseñanza”. En revista DERECHO PUCP. N 48. Revista de la Facultad de Derecho de la Pontificia Universidad católica del Perú. Lima, 2006. Pág. 433. 
y los cursos de especialización bajo la forma de electivos, pero todo ello, también para ir forjando un criterio legal sumado a lo primero.

A través de este proceso de aprendizaje cognitivo el alumno desarrolla además y sobre todo, un criterio o razonamiento legal que sumado a su conocimiento produce una competencia especial para poder ejercer y aplicar esos conocimientos en la práctica. Este criterio legal es adoptado por el estudiante no como el resultado del aprendizaje una materia concreta sino a través del tiempo, en un largo proceso y como el resultado de varios elementos que están presentes en el estudio del contenido de los diversos cursos, como es el caso del manejo de los principios del derecho privado y público, el razonamiento judicial en el estudio de casos, la familiarización con los problemas que debe resolver el derecho, la ética del abogado, la evolución del derecho en el tiempo, la argumentación y el uso del lenguaje especializado como herramienta en el aprendizaje de conceptos legales, etc.

De hecho nadie puede poner en cuestión el "qué" de la enseñanza del derecho sino el "cómo". Y es que basta revisar todas las mallas curriculares para advertir que casi los cursos están presentes en todas las facultades de derecho de un modo u otro. Cada facultad tiene énfasis distintos y de pronto ordenes distintos para los mismos cursos, pero el "cómo" delata la visión que cada una tiene. Hay facultades que ponen énfasis en determinadas materias más que en otras por su visión del derecho y por los profesionales que quieren formar. Otros ponen énfasis en acortar la carrera, y otras en generar una formación más bien integral y menos especializada en pre grado, mientras que otras prefieren enfatizan la opción que los alumnos elijan sus cursos electivos siguiendo sus intereses académicos de modo de generar una malla más especializada y con más opciones.

Años después y ya como docente me he preguntado una y otra vez, si la enseñanza del derecho debía incorporar algo más que solo derecho. Como es evidente, la mayoría de profesores de derecho somos abogados, y probablemente muchos de nosotros no hemos tenido la oportunidad de estudiar educación ni hemos tenido una preparación adecuada para emplear técnicas para enseñar. De hecho, muchos docentes como yo hasta hemos subestimado la necesidad de aprender a enseñar.

Simplemente, enseñamos el derecho como lo aprendimos de nuestros profesores, sumando la vocación y el talento que buenamente podemos tener para dedicarnos a la enseñanza durante algunas horas a la semana. No obstante ello, he podido apreciar que muchos alumnos valoran significativamente las cátedras de las que más han aprendido sin que ello coincida necesariamente con la excelencia o el expertise académico del docente de turno, dejando como balance una valoración positiva al resultado.

Fue con mi intención de mejorar mis habilidades para enseñar que tomé casi por accidente un curso sobre metodologías para la enseñanza del derecho y a partir de allí mis dudas pedagógicas se incrementaron. Como buen abogado estaba predispuesto a defender el patrimonio de la llamada "clase magistral" o de la enseñanza tradicional del derecho incorporando la participación interactiva de los alumnos cada vez que ello era posible; es decir, a sostener que la enseñanza del derecho, tal y como la practicamos, no tiene razones para cambiar significativamente pues el sentido común me llevaba a concluir que bajo ese esquema se han forjado cientos de abogados que han destacado exitosamente en nuestro país ${ }^{4}$.

Sin embargo, comprendí que -desde el plano metodológico-, el derecho como cualquier otra disciplina puede ser transmitida aprovechando los aportes de la ciencia de la educación y los logros de la moderna pedagogía. De hecho hoy en día existen numerosos esfuerzos emprendidos por las distintas facultades de derecho por dotar a los docentes de cursos y talleres dictados

4 MORALES LUNA, Félix F. en ¿En qué conocimientos y habilidades debe ser formado un estudiante de derecho? En revista DERECHO PUCP N ${ }^{\circ}$ 65, Revista de la Facultad de Derecho de la Pontificia Universidad católica del Perú. Lima 2010, Págs.242 243, se pregunta si las practicas pre profesionales son suficientes para generar habilidades y concluye que no lo son, cuestión que ha sido defendida por quienes defienden el modelo tradicional. Todo ello, no tiene que desacreditar los logros de la buena enseñanza académica sumada al talento personal de muchos profesionales. 
por expertos en pedagogía para mejorar las técnicas de enseñanza que van desde el uso de las nuevas tecnologías (plataformas virtuales, redes sociales, trabajos en línea, soportes de información de acceso a bibliotecas virtuales, etc.) hasta metodologías educativas de todo tipo que según cada asignatura pueden mejorar la enseñanza, pero no sólo en el plano cognitivo, sino y sobre todo, desde un plano que busca desarrollar competencias específicas a los alumnos con una enseñanza planificada y orientada a resultados.

No olvidemos que las nuevas tecnologías tienen un impacto directo en la forma cómo se recibe y transmite la información y finalmente en cómo se aprende. Esto es particularmente relevante para la concepción metodológica de toda enseñanza pues la información virtual y su acceso global derivada de la disposición en línea es una condición para las generaciones que crecieron en la era digital alejados del papel.

Todo, ello, sin contar la inclusión de cursos interdisciplinarios en el plan de estudios como derecho y literatura, derecho y cine, inglés jurídico, entre otros muchos.

La presentación por ejemplo de los sílabos por competen- cias es una muestra concreta de ello.

La nueva Ley Universitaria (Ley $N^{\circ}$ 30222) publicada en el diario oficial “El Peruano" el 9 de julio de 2014, incluye el procedimiento de acreditación que deben seguir las distintas universidades del país, que incluye la estructuración por competencias de los cursos ${ }^{5}$. Dicha organización que trae la nueva norma obedece a toda una concepción educativa acerca de la enseñanza que ha adoptado nuestra educación superior $y$ que como es evidente, pone énfasis en las competencias que cada curso debe lograr en el estudiante obligando a cada docente a enfocar el dictado a resultados y a competencias cognitivas y prácticas.

Esta concepción para la elaboración de los sílabos supone que cada asignatura debe estar planificada sobre la base de resultados y articulada en base a competencias específicas que el alumno debe alcanzar en cada contenido lectivo desarrollado. Así, se deben identificar los temas, las competencias, la medición de logros (conceptuales, procedimentales y actitudinales), desplazando en la visión pedagógica el énfasis del "qué" hacia el "para qué" e incluyendo como consecuencia, criterios metodológicos bajo la forma del "cómo" que se conectan, con una evaluación intencio- nal orientada a resultados competenciales.

Con todo lo dicho, podemos advertir que la enseñanza y la concepción misma del derecho en nuestras facultades de derecho se va reconduciendo de modo que el mismo contenido lectivo de la carrera se rediseña a partir de su enseñanza orientada a generar competencias, sin que esta aparente reducción pragmática ponga en cuestión el "qué" del derecho o el protagonismo del saber y del conocimiento como eje central de la enseñanza.

En este contexto, la inclusión -no siempre pacífica-, en muchos planes de estudio de cursos de "destrezas legales", parecen haber generado un creciente interés entre los estudiantes ratificando la necesidad de sumar o cubrir espacios no necesariamente atendidos en diversas mallas curriculares y la valoración del aprendizaje orientado a competencias funcionales.

\section{Destrezas legales}

Debo señalar que la permanente reflexión sobre la enseñanza del derecho ha incluido una serie de aspectos de distinta índole que atraviesa todo proceso de enseñanza superior a lo largo de los años en un país que como todos experimenta cambios a todo nivel. Así, no sólo la eterna dialéctica entre

\footnotetext{
5 “Artículo 40. Diseño curricular.- Cada universidad determina el diseño curricular de cada especialidad, en los niveles de enseñanza respectivos, de acuerdo a las necesidades nacionales y regionales que contribuyan al desarrollo del país. Todas las carreras en la etapa de pregrado se pueden diseñar, según módulos de competencia profesional, de manera tal que a la conclusión de los estudios de dichos módulos permita obtener un certificado, para facilitar la incorporación al mercado laboral. Para la obtención de dicho certificado, el estudiante debe elaborar y sustentar un proyecto que demuestre la competencia alcanzada. Cada universidad determina en la estructura curricular el nivel de estudios de pregrado, la pertinencia y duración de las prácticas pre profesionales, de acuerdo a sus especialidades. El currículo se debe actualizar cada tres (3) años o cuando sea conveniente, según los avances científicos y tecnológicos."
} 
la teoría y praxis ha sido objeto de discusión en la enseñanza del derecho sino que a ello se suman transversalmente otros aspectos como los retos de la profesión del abogado en una sociedad de consumo, el impacto de las nuevas tecnologías, el fenómeno de la globalización y otras transformaciones que inciden simultáneamente al momento de re pensar cómo enseñar Derecho en pleno siglo XXI.

Para MAC LEAN6: "Las destrezas legales son las herramientas o habilidades necesarias para trazar diversas rutas en la labor profesional del abogado. Los lawyering skills, como se les conoce a las destrezas legales en inglés, han sido desarrollados en el sistema anglosajón desde hace varias décadas y constituyen una de las pocas asignaturas obligatorias en la currícula de las Escuelas de Derecho en los Estados Unidos de Norte América y el Reino Unido. Las destrezas legales cobran sentido en la medida en que se entiende el objetivo del Derecho, el de crear reglas de conducta para que las personas puedan vivir en armonía dentro de una sociedad, desde una perspectiva holística. Esto significa mirar al Derecho desde tres dimensiones: la dimensión de los conocimientos, la dimensión práctica y la dimensión personal."

Para esta autora, el curso de destrezas legales incluye la “1. Investigación. 2. Redacción. 3. Capacidad para entrevistar. 4. Defensa y 5 . Negociación."

Por su parte, ZUSMAN ${ }^{7}$, señala que: "Las clases de Legal Skills se desarrollan en sesiones prácticas, donde se focaliza el análisis en el desarrollo de habilidades de trabajo en equipo buscando que el alumno descubra desde el inicio de su carrera, la diferencia existente entre el "cielo de conceptos" y "el pantano de problemas" y que se capacite en el manejo conjunto de los mismos, a fin de aproximarse al problema -y resolverlo- de manera integral. A través de ejercicios simples, muchos de ellos no legales, el profesor va describiendo posibles escenarios de acción de los abogados: la corte, la oficina de aboga- dos, una dependencia pública, donde se plantea un tipo de problemas que los abogados en ejercicio definitivamente afrontan y que lleva a los alumnos a adquirir la convicción de que para resolver un caso, el conocimiento legal es sólo uno de los aspectos a enfrentar. El método se apoya en buena medida en proyección de videos sobre, por ejemplo, informes en la Corte, que los alumnos deben comentar, recurriéndose muy frecuentemente a la técnica de la simulación de casos y hasta a presentaciones teatrales que permitan al alumno descubrir fortalezas y debilidades. Se recomienda a los alumnos llevar un diario, donde deben anotar todo lo que piensan en relación a los ejercicios puestos en práctica, incluyendo el análisis de sus propios sentimientos y percepciones sobre cada uno de los temas tratados en clase."

En un interesante artículo la profesora ZUSMAN ${ }^{8}$, va a señalar -siguiendo el modelo pedagógico de la teoría de Schön-, que el curso de destrezas legales que empezó a dictarse en la facultad de derecho de la

6 MAC LEAN MARTINS, Ana Cecilia, Ob. Cit. Pág. 2.

7 ZUSMAN TINMAN, Shoschana: “Nuevas tendencias en la enseñanza del Derecho: la destreza legal”. Lima, 1999. Documento on line. Incluye como antecedentes y rasgos de las llamadas destrezas legales la siguiente referencia: Los primeros intentos de reforma legal se ubican en Estados Unidos en 1945 con el clinical movement, que comenzó a dar importancia a la práctica pre profesional a través de clínicas legales. Las clínicas revelaron prontamente su insuficiencia y fueron dando paso a cursos de entrevistas a clientes, para desembocar en cursos de razonamiento legal e interpretación de la ley. Más recientemente, la atención ha estado puesta en el desarrollo de un amplio abanico de competencias profesionales, habiéndose acuñado la expresión DRAIN SKILLS: drafting (redacción); research (investigación); advocacy (defensa); interviewing (entrevistas) y negotiation (negociación). Esta corriente ha sido ya acogida por la barra inglesa en el año 1989 y por Law Society en el año 1993 y hoy nadie discute que "Destreza Legal” (legal skills) es una línea de carrera que debe ser incorporada al currículo. (...) Esta tendencia aparece claramente recogida en la agenda para el sector Educación del Reino Unido -Higher Education Meeting the Challenge (1987) donde se plantea que la educación debe servir a las necesidades de la economía, asegurando a los graduandos no sólo su formación para el empleo sino para adquirir la capacidad de estudiar y desarrollarse; para cambiar con el cambio de las organizaciones y para estar preparado a romper los moldes del pasado. Otros programas como el Training Agency's Enterprise in Higher Education Programme proponen como meta fundamental el lograr estudiantes más autónomos y con autoresponsabilidad de seguir educándose a lo largo de su vida."

8 ZUSMAN TINMAN, Shoschana: “Aprendiendo a aprender" en Libro Homenaje a Jorge Avendaño. Fondo Editorial de la Pontificia Universidad Católica del Perú. Lima, 2004. Págs.238-239. 
Pontificia Universidad Católica desde el año 2003, está orientado a desarrollar y potenciar las habilidades de redacción, investigación, defensa, entrevistas y negociación.

Con ello, podemos señalar que el curso de destrezas legales busca desarrollar o potenciar determinadas habilidades necesarias para el aprendizaje y ejercicio del derecho de modo que en forma intencional $y$ planificada los alumnos puedan acceder en forma sistemática a una gama de necesarias habilidades que todo abogado empleará en el ejercicio de la profesión.

Ya varias facultades de derecho marcan una clara tendencia en la inclusión de este tipo de cursos en sus mallas curriculares, (Pontificia Universidad Católica del Perú, Universidad de Ciencias Aplicadas (UPC), Universidad del Pacífico, Universidad de Lima, etc.).

No obstante ello, en su momento surgió, un leve debate o resistencia sobre la pertinencia y necesidad de la inclusión del curso de destrezas legales en el plan curricular.

Resulta revelador el debate suscitado entre la profesora ZUSMAN, y los profesores CASTILLO FREYRE Y VASQUEZ KUNZE a propósito de la inclusión del curso de destrezas legales dictado en la facultad de derecho de la Pontificia Univer- sidad Católica del Perú, desde el año $2003^{9}$.

Por un lado CASTILLO FREYRE y VÁSQUEZ KUNZE, critican el modelo en que se basa el curso de destrezas legales, acusándolo de pretender ser "el modelo de enseñanza" por encima de otros citando los postulados que fueron en su momento desarrollados en el antes citado artículo de la profesora ZUSMAN "Aprendiendo a aprender". Agregan que el modelo escolástico de enseñanza que se critica como antecedente para justificar esta nueva visión sobre la enseñanza del derecho ha sido varias veces modificado. Asimismo, señalan los autores que este nuevo modelo está basado en una cultura ajena como la anglosajona que nada tiene en común con la nuestra y que no existe pues un modelo universal. Finalmente, critican la reforma curricular por haber quitado desde hace varios años los cursos de prácticas para sustituirlos por los llamados cursos o seminarios de integración ${ }^{10}$.

Señalan estos autores: "Nos guste o no, nuestra tradición jurídica es la romano-germánica y a ésta corresponde una educación legal que privilegia la información como el conocimiento relevante sobre la metodología de enseñanza y las habilidades que ésta fomenta. Lo contrario, teniendo en cuenta que no se pretende ni se ha pretendido jamás cam- biar nuestra tradición jurídica por la anglosajona, sería -y ha sido, aunque hasta ahora en menor medida - el error de las reformas de la enseñanza del Derecho que se esgrimen recurrentemente en nuestra Facultad de tiempo en tiempo."

Por su parte, ZUSMAN cuestiona en la posición anterior que se crea que la enseñanza del derecho y sus métodos (materializados en la enseñanza de las destrezas legales) pretendan resolver problemas de un sistema jurídico en particular, cuando en realidad se trata de herramientas que todo abogado -donde ejerza- requerirá:

“La enseñanza de habilidades es un requerimiento para cualquier profesional en cualquier parte del mundo, independientemente de la tradición jurídica a la que pertenezca. No se circunscribe, pues, a los requerimientos de la práctica anglosajona. Nadie duda -creo yo- que saber redactar; saber exponer; saber investigar o saber entrevistar, son cualidades que no dependen, ni mucho menos, de una determinada tradición jurídica. Así como los médicos, los ingenieros o los arquitectos requieren una formación en habilidades, independientemente del lugar en el que ejercerán su profesión, los abogados requieren idéntica formación para poder desempeñarse en la práctica profesional. Si los países de tradición romano-germánica no consideraron la enseñan-

Shoschana Zusman Tinman versus Mario Castillo Freyre y Ricardo Vásquez Kunze: “Cómo se debe enfocar la educación legal? En THEMIS N 57, Revista de Derecho. Pontificia Universidad Católica del Perú. Lima, 2009.

10 GONZALES MANTILLA, Gorki, en “Enseñanza del Derecho y Cultura Legal" en Revista de DERECHO PUCP. Revista de la Facultad de Derecho de la Pontificia Universidad católica del Perú. Lima 2007, Pág. 92-93, ya analizaba el impacto de los llamados curso de integración relativizando el peso de las llamadas reformas innovadores. 
za de habilidades como parte de la currícula de sus universidades, no es porque dicho aprendizaje no es compatible con el sistema, sino, simplemente, porque, en un momento determinado, no vieron el problema. Hoy, sí lo ven. b) Tampoco se trata de que el sistema anglosajón sea "un sistema enraizado en el show business"...ni que el abogado norteamericano tenga que verse con una "tradición jurídica operística y oral”, que según los profesores Castillo y Vásquez, no aplica a los abogados formados en la tradición romano germánica. Esa es una mirada caricaturesca del abogado anglosajón, no sólo porque, unos pocos juicios se desarrollan con el sistema de jurado, sino porque la abogacía es bastante más amplia y compleja que el simple aprendizaje de reglas de comunicación para un público iletrado. Piénsese, nada más, en otras áreas de la profesión, que nada tienen que ver con el litigio, como son Propiedad, Contratación, Derecho Tributario o Derecho Administrativo, que exigen ciertas habilidades, que no se centran en la comunicación oral. c) Los profesores Castillo y Vásquez no demuestran cómo así a cada tradición jurídica corresponde una determinada metodología de enseñanza; ni dan razones por las cuales la tradición romano-germánica privilegia la información sobre la formación en habilidades. $\mathrm{Y}$, en $\mathrm{mi}$ opinión, no hay nada en la tradición romano-germánica que imponga el método magistral ni, mucho menos, que privilegie la transmisión de información sobre el aprendizaje. La metodología de la enseñanza depende, más bien y, en primerísimo lugar, del avance de la pedagogía, que propone nuevas maneras de enseñar (Schön; Barnett; Piaget; Kolb); de una determinada visión del Derecho y de una idea clara por parte de las autoridades universitarias del tipo de abogado que quieren formar. Es cierto que el Realismo Norteamericano impulsó fuertemente la orientación de la enseñanza del Derecho al análisis de problemas reales, pero eso no quiere decir que eso no pueda ser replicado en el sistema romano germánico que, finalmente, comparte raíces con la tradición jurídica anglosajona. d) Por lo demás, hoy se viene produciendo un acercamiento entre los sistemas jurídicos anglosajón y romano-germánico, muestra de lo cual es, por ejemplo, el abandono del razonamiento silogístico, a punto que se dice que "hoy ningún abogado en Francia mantiene seriamente el punto de vista según el cual las decisiones judiciales se determinan por la operación formal, para no llamarla mecánica, del silogismo, sin tomar en cuenta las consecuencias de una determinada situación fáctica", que es lo que caracteriza a la administración de justicia anglosajona. e) Hoy en día, el sistema anglosajón ya no se circunscribe al common law. Tanto en Estados Unidos como en el Reino Unido, se ha expedido (y se sigue expidiendo) abundante legislación en todos los campos, incluyendo códigos, leyes generales y reglamentos. Y, en eso, no se distingue en nada del Derecho continental, para lo cual basta con revisar un texto de statutory interpretation, para apreciar que los anglosajones aplican exactamente los mismos métodos de interpreta- ción que los que se utilizan en la tradición romano-germánica. Y, aún en esta nueva circunstancia de desplazamiento hacia la legislación, los anglosajones siguen impulsando el aprendizaje de habilidades y la utilización de la metodología activa de enseñanza, sin haber nunca planteado, hasta lo que yo sé, que la adopción del sistema legislativo impone el retorno al método magistral o un sistema que privilegie la información. f) Finalmente, vivimos en un mundo globalizado donde, nos guste o no nos guste, la cultura anglosajona se ha impuesto. El inglés es hoy, el idioma universal; Estados Unidos es el centro científico del mundo, donde la investigación ha tenido y sigue teniendo resultados impresionantes; las universidades norteamericanas son siempre las mejor rankeadas; su tecnología es la más avanzada; abundan los premios Nobel en todas las áreas científicas y artísticas; se practica la mejor medicina, la mejor ingeniería y la mejor economía del mundo $y$, finalmente, su cultura se exporta, con lo bueno y lo malo que eso tiene (las "macburgers"; Hollywood; el jazz y su extraordinaria literatura). En el ámbito jurídico, las cosas no son muy distintas: la contratación ha cambiado en todas partes del mundo, gracias a nuevas figuras provenientes del mundo anglosajón; dicha tradición ha influido también en el cambio del concepto de propiedad (time sharing), que estoy segura, pronto adoptaremos; su razonamiento judicial (primero la conclusión y luego la premisa) ha sido adoptado sin dificultad por abogados de tradición romano-germánica, que han abandonado (cons- 
ciente $\mathrm{o}$ inconscientemente) el silogismo, como esquema esencial de pensamiento. Incluso, se viene adoptando un nuevo estilo judicial que aspira, al mejor estilo anglosajón, a la simplificación del lenguaje judicial28. Decir, entonces, que el sistema anglosajón nos es ajeno, es, por lo menos, exagerado. Posiblemente esa preponderancia no persista por mucho tiempo más y que, de acá a 100 años resulten más interesantes el sistema musulmán o el chino. Pero hoy no cabe duda de que el mundo anglosajón lleva la delantera, aún con la crisis que él mismo ha creado."

Con esta réplica no queda mucho por agregar.

Recientemente, en una mesa redonda Mesa Redonda llevada a cabo el día 18 de diciembre de 2015, los miembros del Consejo Editorial de THËMIS-Revista de Derecho de la PUCP, tomaron de varios profesores la importancia de la enseñanza de las destrezas legales ${ }^{11}$. La gran conclusión fue que la tanto la comunicación, como la persuasión, el saber vender una idea, el planeamiento, el estudio del caso entre otras, son habilidad que generan indudables competencias en los abogados y deben complementar el conocimiento teórico.

Como balance general es necesario decir que este tipo de cursos no tiene por objeto palear ni mucho menos resolver los viejos problemas sobre la enseñanza del Derecho. Las destrezas legales, en contrario a lo que piensan algunos, no pueden ser forjadas en los estudios generales. $Y$ es que si bien en esta etapa el alumno desarrolla muchas habilidades (lectura, análisis, investigación, etc.) este desarrollo o aprendizaje no planificado ni intencional no producirá resultados en todos los alumnos por igual, y por otro lado, se encuentra muy alejado y desconectado de los cursos de derecho, momento en el cual un alumno puede advertir y conectar y aplicar sus habilidades con el aprendizaje teórico.

Está claro que las destrezas legales no se agotan en el ámbito del litigio, y que muchas de ellas constituyen verdaderas herramientas en todo ámbito de desempeño del futuro abogado. Demás está decir que las habilidades para ejercer una profesión no pueden limitarse o circunscribirse a una determinada cultura legal.
Creo que el punto de inflexión no radica en derribar ningún modelo de enseñanza, pero si reconducir ciertos criterios que pueden mejorar las destrezas legales de todo profesional del derecho. Es verdad que no se trata de menuda cosa, porque la pregunta previa siempre será y ¿qué tipo de abogados queremos forjar? ¿Cuál es nuestra visión de lo que un abogado debe aprender y cómo lograrlo?

En una sociedad y en un mercado cada vez más exigente y competitivo, resulta impensable no planificar o dotar a los alumnos de recursos y/o habilidades y/o destrezas que les ayuden a ejercer la abogacía, sin que ello suponga de construir el modelo de aprendizaje basado en conocimientos, pues los cursos de destrezas legales complementan y permiten explotar en el terreno de la práctica el conocimiento legal.

\section{Las competencias para estu- diantes}

Desde hace años, distintas instituciones (estudios de abogados, universidades, etc.) han venido organizando las llamadas competencias o "moots"12, como una propuesta académica para estudiantes con el fin

11 MESA REDONDA: Huáscar Ezcurra, José María de la Jara, Nicolás de la Flor, Pablo Mori: “La Importancia de las Destrezas Legales en la Actualidad”. Revista THEMIS. Pontificia Universidad Católica del Perú. N68, Lima, 2015.

12 CONOVE, Ana: Los moot courts suponen la participación en concursos de Derecho -nacional o internacionalque implican la preparación, exposición y defensa legal de un caso ficticio. Generalmente constan de dos fases: una primera que es escrita y la segunda que se desarrolla de manera oral. Durante la primera fase los equipos realizan un análisis de los hechos del caso, así como de las disposiciones jurídicas aplicables al mismo, doctrina y precedentes relevantes para la elaboración de una demanda y una contrademanda, respectivamente. Una vez publicado el caso, los equipos constan con un determinado número de meses para dedicarse a la investigación y redacción de los escritos. Finalizados los escritos, inicia la segunda y quizás la más divertida etapa del mooting: la fase oral. En ella, los equipos deberán prepararse para estructurar sus argumentos y defenderlos ante un panel de expertos en la simulación de una audiencia. En esta, podrán ser interrumpidos y cuestionados en cualquier momento a lo largo de su exposición por los miembros del panel o corte y deberán estar preparados para contestar de manera breve y concisa, así como concluir su presentación en el tiempo establecido para ello. https://aquiescencia.net/2010/11/01/\%C2\%BFque-es-un-moot-court-y-por-que-interesa-saberlo/. 
de desarrollar habilidades vinculadas al litigio bajo el formato de debate ${ }^{13}$.

Desde el punto de vista pedagógico estas competencias promueven en forma directa e intencional el desarrollo y fortalecimiento de una serie de habilidades y competencias en los futuros abogados -aun cuando no tengan vocación de litigio-, pues estos espacios obligan a los participantes a trabajar en equipo, analizar un caso, investigar los hechos, aplicar en forma específica el marco legal elegido por la competencia, diseñar una estrategia legal, redactar escritos de demanda y contestación, afrontar la exposición oral del caso, debatir públicamente con otros equipos, interactuando con jurados conformados por abogados experimentados.

De muchas de ellas, las que tienen por objeto llevar a concurso temas vinculados a litigios arbitrales han servido además para promover el estudio y desarrollo del arbitraje. Nótese que el desarrollo y crecimiento del arbitraje en nuestro país ha puesto en escena la necesidad de que muchos abogados familiarizados con la práctica procesal de nuestras cortes tengan que re aprender a litigar.

Y es que nuestro país está adscrito a un sistema judi- cial propio de nuestra tradición jurídica donde el rol del abogado en las cortes resulta muchas veces formalista, y de poca relevancia pues: (i) los jueces encargados de conocer miles de causas casi no pueden dedicarle mucho tiempo a un caso en concreto; (ii) el tiempo para informar y debatir ante un magistrado o corte por lo general resulta insuficiente; (iii) muchos jueces no son especialistas en la materia objeto de controversia; (iv) No existen muchas facilidades para emplear recursos multimedia; ( $v$ ) Existe un énfasis en la postulación escrita de las posiciones de las partes por encima de la oralidad, etc.

Sin embargo, la práctica del arbitraje de un cierto modo revierte este panorama, pues los árbitros están más dispuestos a conocer el caso en concreto y tienden a oír a las partes y sus abogados, pues se trata de una justicia especializada, que se abocará a la revisión más detenida de la prueba, y todo esto, obliga a que los abogados tengan una mayor demanda en su preparación, pues además deben conocer las reglas y normas que rigen el arbitraje pues también tendrán que afrontar cuestiones legales de estricta índole arbitral.

Estas competencias de estudiantes cuando son internacio- nales agregan un componente interesante pues permiten a los estudiantes interactuar con alumnos forjados bajo distintas legislaciones e incluso bajo distintos sistemas jurídicos de modo que la experiencia resulta particularmente enriquecedora.

El trabajo con el estudio y resolución de casos ha sido desde que era estudiante de pre grado la forma tradicional de llevar a la práctica el conocimiento teórico del derecho. De una forma u otra, el trabajo con casos (si eran reales mejor) es una experiencia que ayuda a aterrizar y aplicar figuras o principios aprendidos en clase de un modo específico para resolver una situación que además enfrenta a dos partes. Si bien no solía haber debate, era claro que esta metodología aportaba de manera directa al desarrollo y fortalecimiento de muchas destrezas legales entre los alumnos.

En el caso de las competencias de estudiantes bajo el formato de debate sobre casos en el que cada equipo debe defender una posición, asistimos una mejor versión de la simple resolución y trabajo de casos prácticos que se imparten en pregrado. La sola idea de competir imprime en los estudiantes la necesidad de agotar todos los recursos para lograr construir una posición o estra-

13 Tal es el caso del Campeonato Mundial Universitario de Debate en Español, CEMUDE: “El Campeonato Mundial Universitario de Debate en Español (C.M.U.D.E.) nació en 2011 como la versión hispanohablante del World Unviersities Debate Championship anglosajón con más de 40 años de andadura. De esta manera, el CMUDE es la mayor y más importante competición de debate en habla hispana, enfocada desde, por y para los estudiantes universitarios, y tiene lugar anualmente cada verano en una Universidad. En él participan cada año decenas de debatientes y jueces de habla hispana de todo el mundo, para fomentar las habilidades de la oratoria, la argumentación y el pensamiento crítico. El formato de la competición es el llamado British Parliament (BP) o formato parlamentario, en el que en cada debate participan cuatro equipos ejerciendo dos de ellos los roles de gobierno y los otros dos los roles de oposición, para argumentar sobre una moción dada quince minutos antes de que comience el debate", o de la Competencia de Arbitraje de la UBA y de la Universidad del Rosario de Bogotá, entre otras muchas. 
tegia que quede impecablemente redactada y que pueda convencer al jurado. Si a ello se suma que la competencia te enfrentará con estudiantes de derecho de otros países, el desafío se incrementa.

Además de ello, existe toda una preparación para la fase oral, en la que con tiempo hay que organizar una buena línea o guión que pueda ser articulada en forma eficiente que persuada mejor que la contraria, sin contar con la presión del mismo jurado. La teatralización, la oratoria, y la persuasión en general juegan un partido aparte.

La investigación, diseño de estrategia, redacción de escritos postulatorios (memorias) y fase oral, redondean toda una labor que en sí misma ya es una forma de mejorar las destrezas legales. Todo ello además considerando que el caso propuesto generalmente es amplio y rico en temas, pues se conjugan temas contractuales, temas relativos a contratación con el estado, temas de arbitraje, de responsabilidad civil, de derecho administrativo, etc.

Otro factor que enriquece este tipo de competencias es el tiempo que tienen los equipos para prepararse. En el caso de competencia de la UBA y de la Universidad del Rosario de Bogotá que uso de ejemplo, los casos son publicados en el mes de marzo y la fase oral tiene lugar entre los meses de setiembre y octubre del mismo año. La fase escrita debe agotarse casi tres meses después de publicado el caso, de modo que los alumnos pueden prepararse con anticipación haciendo de la fase oral una etapa muy competitiva.

La competencia de la UBA (Argentina) y de la Universidad del Rosario de Bogotá (Colombia)

Como ejemplo de estas competencias de estudiantes, podemos tomar la competencia anual para estudiantes que organizan la Universidad de Buenos Aires (UBA) de Argentina y la Universidad de Rosario de Bogotá, Colombia.

Según la propia página o portal de la competencia se define a esta competencia en los siguientes términos:

"La Competencia es una propuesta educativa con formato competitivo, cuyo propósito es fomentar el estudio del derecho comercial internacional y el arbitraje como método de resolución de conflictos. Para ello, alumnos de distintas universidades actúan como abogados de las partes en un caso simulado, debiendo defender los intereses de sus hipotéticos clientes (primero en forma escrita y luego en forma oral) frente a tribunales arbitrales integrados por prestigiosos árbitros internacionales, abogados y académicos, quienes tienen a su cargo la tarea de evaluar y calificar las presentaciones, tanto escritas como orales, de los equipos. La Competencia, que nació como una iniciativa de la Universidad de Buenos Aires y a la cual luego se sumó, como co-organizadora, la Universidad del Rosario de Bogotá, ha demostrado ser una eficaz herramienta para la enseñanza y el entrenamiento del arbitraje a los futuros abogados. Diseñada para formar a alumnos universitarios en la teoría y la práctica del arbitraje internacional, la Competencia ofrece un ámbito de excelencia para el mundo hispanoparlante, al poner a los estudiantes en el rol de abogados de ambas partes en un proceso arbitral internacional, defendiendo a hipotéticos clientes en un caso especialmente creado para ello. Las reglas de procedimiento y normas aplicables pueden variar según las circunstancias que el caso plantee en cada edición, pero normalmente involucra el estudio de la Ley Modelo de Arbitraje Comercial de CNUDMI/UNCITRAL, así como las Convenciones sobre reconocimiento y ejecución de sentencias arbitrales extranjeras (Nueva York 1958 y Panamá 1975) y, eventualmente, los Principios UNIDROIT sobre Contratos Comerciales Internacionales."

En su primera edición llevada cabo el año 2008, en Buenos Aires, participaron 6 equipos ${ }^{14}$ de 4 países, incluida la parti-

14 En la primera edición (Buenos Aires, 2008), el caso se refería a una compraventa internacional de mercaderías, con aplicación de la Convención de Viena sobre Compraventa Internacional de Mercaderías, y del reglamento de arbitraje de CNUDMI/UNCITRAL. Participaron de esta primera edición 6 equipos de 4 países, representativos de las siguientes universidades: Universidad de Buenos Aires (Argentina), Universidad Argentina de la Empresa (Buenos Aires, Argentina), Universidad Nacional de Tucumán (Argentina), Escuela Superior de Economía y Negocios (El Salvador), Universidad Privada de Santa Cruz (Bolivia) y Universidad Privada de Ciencias Aplicadas (Lima, Perú). 
cipación del equipo de la Universidad de Ciencias Aplicadas de Perú (UPC).

Sólo al año siguiente, 2009, participaron 24 equipos de 9 países: de Argentina: Universidad Austral, Universidad Argentina de la Empresa, Universidad Nacional de Rosario, Universidad Nacional de Córdoba, Universidad Nacional de Mar del Plata, Universidad de Belgrano, Universidad Blas Pascal, Universidad Nacional de La Plata, Universidad de Buenos Aires y Universidad Católica Argentina; de Chile: Universidad Católica de Valparaíso, Universidad Andrés Bello, Pontificia Universidad Católica de Chile y Universidad Adolfo Ibáñez; de Colombia: Universidad Nacional de Colombia y Universidad del Rosario; de Ecuador: Universidad Católica Santiago de Guayaquil; de Panamá: Universidad de Panamá; de Paraguay: Universidad Católica de Paraguay y Universidad Nacional de Asunción; de Perú: Universidad Peruana de Ciencias Aplicadas y Pontificia Universidad Católica de Perú; de Uruguay: Universidad de Montevideo; de Venezuela: Universidad Monteávila.

La última edición de la competencia llevada a cabo el 2015 (VIII Edición) tuvo lugar en Santiago de Chile, entre el 25 y el 28 de septiembre de 2015 , en las aulas de la Pontificia Universidad Católica de Chile, que ofició de anfitriona y sede de la fase oral. Participaron de esta edición 45 equipos de universidades públicas y privadas de 13 países: Argentina (7), Bolivia (3), Chile (5), Colombia (6), Costa Rica (1), Ecuador (3), EE.UU. (2), Francia (1), Guatemala (1), México (1), Paraguay (2), Perú (12) y Uruguay (1), conforme detalle en Anexo al final de este informe.

La edición 2016 con sede en Montevideo Uruguay, que ya se inició cuenta con 51 equipos en total de 14 países, de cuales 9 son peruanos, representados por equipos de las siguientes universidades; Universidad Peruana de Ciencias Aplicadas (UPC), Pontificia Universidad Católica del Perú (PUCP), Universidad de Lima, Universidad ESAN, Universidad Femenina del Sagrado Corazón (UNIFE), Universidad Católica de Santa María de Arequipa, Universidad del Pacífico, Universidad Nacional Mayor de San Marcos y Universidad Católica San Pablo (Arequipa).

\section{BALANCE}

Estos datos ponen en evidencia el creciente interés de los alumnos por participar en esta clase de competencias, y nuestro país no es ajenos a ello, sin perjuicio que el desarrollo y la creciente práctica del arbitraje en nuestro medio colabora también en impulsar estas iniciativas académicas que sin lugar a dudas contribuye a mejorar las des- trezas legales en los futuros abogados.

Pensar que hoy en día la adquisición de las destrezas legales como parte de la fase del aprendizaje práctico del derecho se reduce a las aulas, ya sea a través de las clases prácticas -cuando ellas existen-, o al lejano aporte de los estudios generales, o a la experiencia desigual y fortuita que aportan las prácticas pre profesionales, es desconocer las fortalezas que aportan estas habilidades en los estudiantes si son forjadas y estimuladas desde las distintas actividades, cursos y espacios académicos que pueden generarse. Así participar en una revista de estudiantes de derecho, en círculos de estudios, en la organización de eventos académicos, en competencias de debates, en talleres orientados a desarrollar destrezas para redactar, comunicar, etc., son sólo una forma de procúraselos.

En un mercado cada vez más competitivo y globalizado, dotar a los estudiantes de derecho de destrezas legales es reconocer su aporte a la formación del futuro abogado para mejorar su aprendizaje y rendimiento. $Y$ es que el saber tiene muchas expresiones, el saber hacer, saber imaginar, saber decir, saber leer, etc., y todas ellas, forman parte de un permanente aprendizaje, porque los abogados nos hacemos todos los días. 